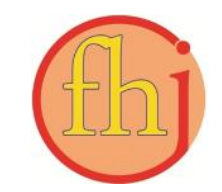

Faletehan Health Journal, 8 (1) (2021) 36-41

www. journal.Ippm-stikesfa.ac.id/ojs/index.php/FHJ

ISSN 2088-673X | e-ISSN 2597-8667

\title{
Hubungan Kondisi Psikososial Dan Paritas Dengan Kejadian Depresi Postpartum Pada Ibu Remaja
}

\author{
Ariani Fatmawati ${ }^{*}$, Nina Gartika ${ }^{1}$ \\ ${ }^{1}$ Universitas Aisyiyah Bandung \\ *Corresponding Author: rianiners@gmail.com
}

\begin{abstract}
Abstrak
Angka kejadian depresi postpartum pada ibu remaja setiap tahun semakin meningkat. Ketidaksiapan dalam menerima peran baru merupakan salah satu penyebab dari peningkatan ini. Penelitian terdahulu telah menemukan factor-faktor yang mempengaruhi kejadian depresi postpartum, akan tetapi khusus penelitian yang membahas hubungan kondisi psikososial dan paritas dengan kejadian post partum masih sangat terbatas. Penelitian ini bertujuan untuk mengetahui kondisi psikososial dan paritas dengan kejadian depresi postpartum. Jenis penelitian kuantitatif dengan metode cross sectional untuk menganalisis variabel independen dengan variabel dependen. Sampel diambil dengan consecutive sampling sebanyak 90 ibu. Analisis data bivariat dengan chi square. Hasil penelitian menunjukkan terdapat hubungan yang signifikan antara kondisi psikososial dengan kejadian depresi postpartum $(p=0,007)$, sementara tidak terdapat hubungan antara paritas dengan kejadian depresi postpartum $(p=0,180)$. Disarankan bagi peneliti selanjutnya dapat melakukan penelitian tentang efektivitas pemberian terapi qur'anic healing bagi ibu remaja yang mengalami depresi post partum.
\end{abstract}

Kata Kunci: Depresi Postpartum, Ibu Remaja, Kondisi Psikososial, Paritas

\section{The Relationship of Psychosocial Condition and Parity with Postpartum Depression Incidence in Adolescent Mothers}

\begin{abstract}
The incidence of postpartum depression in adolescent mothers is increased every year. Unpreparedness in accepting the new role is one of the causes of this increase. Previous studies have found factors that influence the incidence of postpartum depression; however, specific studies that discuss the relationship between psychosocial conditions and parity with postpartum incidence are still very limited. The purpose of this study was to determine the psychosocial condition and parity with the incidence of postpartum depression. This is a quantitative research with cross-sectional method to analyze the independent variables by the dependent variables. The samples were taken by consecutive sampling of 90 mothers. The bivariate data was analyzed by using chi-square. The results showed a significant relationship between psychological conditions and the incidence of postpartum depression $(p=0.007)$; while there is no relationship between parity and the incidence of postpartum depression $(p=0.180)$. The results of this study can be used as an input for health workers to screen postpartum depression during pregnancy.

Keywords: Postpartum Depression, Adolescent Mothers, Psychosocial Condition, Parity
\end{abstract}


Faletehan Health Journal, 8 (1) (2021) 36-41

\section{Pendahuluan}

Postpartum merupakan suatu periode yang ditandai dengan adanya perubahan peran, perubahan fisik dan psikologis bagi seorang ibu. Adaptasi fisiologis dan psikologis tidak mudah bagi seorang ibu (Habel et al., 2015). Perubahan ini dirasakan berat terutama kemampuan afektif, dan $85 \%$ ibu mengalami gangguan mood (Sylvén et al., 2017) dengan 10-15\% yang berkelanjutan menjadi depresi postpartum (Cirik et al., 2016).

Gangguan mood yang terjadi pada ibu postpartum dan berlangsung sampai satu tahun sering disebut dengan depresi postpartum (Qobadi et al., 2016). Beberapa gejala depresi postpartum seperti sering menangis tanpa sebab, perasaan sedih, mudah tersinggung, tidak nafsu makan, insomnia, kelelahan, sulit beraktifitas, kecurigaan yang tinggi terhadap sesuatu hal, kurang perhatian, menyalahkan diri sendiri, tidak memiliki harapan, kurang memperhatikan bayinya bahkan kadang mengabaikan bayinya, dan memiliki perasaan tidak mampu berperan sebagai ibu (Reeder et al., 2012).

Kejadian depresi postpartum dipengaruhi oleh beberapa faktor seperti usia, paritas, status ekonomi, dukungan sosial (Nurfatimah \& Entoh, 2018). Faktor risiko kejadian depresi postpartum yaitu hubungan perkawinan yang buruk, sosial ekonomi rendah, pendidikan rendah, depresi prenatal, penyakit masa anak-anak, obesitas, kehamilan yang tidak diingankan, riwayat gangguan mental, dan selama masa hamil mengalami komplikasi (Putriarsih et al., 2017). Kondisi psikososial ibu dapat meningkatkan kejadian depresi postpartum (Tietz et al., 2014).

Prevalensi kejadian depresi postpartum di 27 negara sepanjang tahun 2004-2012 adalah sebesar 11,5\% (Ko et al., 2017), sekitar 3,5\%-63,3\% terjadi di Asia (Yusuff et al., 2015). Kejadian ini meningkat di negara-negara dengan pendapatan menengah kebawah, angka kejadian depresi postpartum $1,9 \%-82,1 \%$ dan dinegara yang berpenghasilan menengah keatas sebesar 5,2\%74\% (Tikmani et al., 2016). Angka kejadian depresi postpartum pada ibu remaja sebanyak $15 \%$ (J. Young et al., 2010), 55,6\% (A. Fatmawati \& Gartika, 2019). Kejadian depresi postpartum selain terjadi pada ibu dewasa, kejadian ini juga sering terjadi pada ibu remaja.

Ibu remaja adalah perempuan yang berusia remaja 10-21 tahun (BKKBN, 2013) yang telah melahirkan. Prevalensi kelahiran pada ibu remaja yang berusia 15-19 tahun adalah 26,5 kelahiran dari total kelahiran 273.105 bayi di Amerika Serikat (Martin et al., 2017). Jumlah kelahiran ibu remaja di Kanada 11 kelahiran drai 1000, di Jerman 7 kelahiran dari 1000 dan di United Kingdom 17 kelahiran dari 1000. Tingginya prevalensi kelahiran ibu remaja akan meningkatkan risiko depresi postpartum.

Angka kejadian depresi postpartum pada ibu remaja rata-rata berkisar 25\% (Dinwiddie et al., 2018). Faktor risiko ibu postpartum remaja mengalami depresi postpartum adalah konflik keluarga, primipara, harga diri rendah (MeltzerBrody et al., 2013), merasa tidak puas terhadap bentuk tubuh (Zaltzman et al., 2015), kurangnya dukungan sosial (Nunes \& Phipps, 2013), dan kondisi emosional yang belum stabil (A. Fatmawati et al., 2018).

Depresi postpartum memiliki dampak jangka panjang untuk kesehatan mental ibu dan pada perkembangan fisik, kognitif dan sosial anak-anak (Borra et al., 2015). Ibu akan menghentikan pemberian ASI. Bayi yang tidak diberikan ASI lebih dari 9 bulan tidak memperlihatkan perkembangan kognitif yang signifikan dibandingkan dengan bayi yang mendapatkan ASI lebih dari 9 (Lee et al., 2016). Dampak lain akan menyebabkan ikatan tali kasih ibu dan anak terganggu (Bicking Kinsey \& Hupcey, 2013; A. Fatmawati et al., 2018).

Dampak depresi postpartum terhadap keluarga dapat menyebabkan anggota keluarga mengalami kecemasan dan stress, terutama suami akan merasakan kehilangan sosok istri, merasa tidak bisa mengendalikan emosi, cemas, tidak tahu apa yang harus dilakukan, dan mudah marah. Hal ini akan berdampak buruk terhadap kehidupan rumah tangga (Chabrol \& Challahan, 2007; Fitelson et al., 2010).

Penelitian ini bertujuan untuk mengetahui hubungan kondisi psikososial dan paritas dengan kejadian depresi postpartum pada ibu remaja.

\section{Metodologi Penelitian}

Penelitian ini adalah penelitian kuantitatif dengan pendekatan analitik dan desain yang digunakan cross sectional. Populasi pada penelitian ini yaitu ibu postpartum yang berusia remaja sebanyak 252 orang. Teknik sampling yang digunakan dengan consecutive sampling sebanyak 90 sampel sesuai dengan kriteria inklusi dan 
eksklusi. Kriteria inklusi pada penelitian ini adalah ibu postpartum usia 12-21 tahun, postpartum hari 1-14 hari. Kriteria eksklusinya adalah ibu postpartum remaja yang mengalami komplikasi persalinan. Penelitian dilakukan di RSKIA Kota Bandung, RSUD Al-Ihsan Kab. Bandung, dan Bidan Praktik Mandiri Imas Mardinarsyah, S.ST.,M.Tr.Keb. Penelitian dilakukan pada bulan Mei-Agustus 2019. Kuesioner yang digunakan adalah Edinburgh Postpartum Depression Scale (EPDS) untuk mengukur depresi postpartum dengan hasil uji validitas 0,875 dan hasil uji reliabilitas 0.76 (Machmudah, 2010), dan Postnatal Riskquestionnaire (PNRQ) untuk mengukur kondisi psikososial ibu dengan hasil uji validitas 0,630-0,963 dan uji reliabilitas dengan nilai Cronbach's Alpha 0,938 (Kurniawati, 2015). Penelitian ini sudah mendapatkan surat ijin etik dari KEP STIKes Aisyiyah Bandung dengan nomor 23/KEP. 02/STIKes-AB/X/2019.

Analisa data dalam penelitian ini terdiri dari analisis univariat dan bivariat. Analisis univariat digunakan untuk mengidentifikasi prevalensi kondisi psikososial, paritas dan kondisi depresi postpartum. Analisis bivariat mengunakan chi square yang bertujuan untuk mengidentifikasi hubungan kondisi psikososial dan paritas dengan kejadian depresi postpartum.

\section{Hasil dan Pembahasan}

Berdasarkan hasil tabel 1 menunjukkan bahwa kejadian depresi postpartum pada ibu remaja sebanyak 55,5\%, kondisi psikososial berisiko sebanyak $31,1 \%$ dan paritas paling banyak primipara $(85,6 \%)$.

Berdasarkan hasil penelitian didapatkan bahwa yang berhubungan dengan kejadian depresi postpartum pada ibu remaja adalah kondisi psikososial. Hasil penelitian ini sejalan dengan
Çankaya, (2020) yang menyatakan bahwa ibu yang mengalami gangguan psikososial cenderung mengalami depresi pasca partum. Faktor risiko gangguan psikososial enam kali berisiko terjadi depresi postpartum (Christl et al., 2013). Menurut Zelkowitz et al (2014), 33 \% ibu dengan resiko kondisi psikososial mengalami depresi persalinan.

Gangguan psikologis pada bulan kedua sampai ketiga berisiko terjadi depresi postpartum (Edhborg et al., 2011). Bentuk gangguan psikologis pada ibu postpartum remaja yaitu kecemasan yang berkepanjangan (Moynihan, 2014). Kondisi psikologis pada ibu postpartum berupa kecemasan, kelelahan dan perubahan fisik (Tietz et al., 2014; R. Young, 2013). Dukungan sosial juga berpengaruh terhadap depresi postpartum. Kondisi sosial seperti kondisi pernikahan yang tidak baik, kurangnya dukungan dari pasangan dan keluarga, dan mengalami tekanan fisik, psikologis dan sosial selama kehamilan berhubungan dengan kejadian depresi postpartum (Çankaya, 2020; Coburn et al., 2016).

Hasil analisis penelitian dapat dilihat pada tabel dibawah ini:

Tabel 1. Distribusi Frekuensi Kondisi Psikososial, Paritas dan Kejadian Depresi Postpartum

\begin{tabular}{lcc}
\hline \multicolumn{1}{c}{ Variabel } & f & \% \\
\hline Kondisi Psikososial & & \\
\hline Tidak Beresiko & 62 & 68,9 \\
\hline Berisiko & 28 & 31,1 \\
\hline Paritas & & \\
\hline Primipara & 77 & 85,6 \\
\hline Multipara & 13 & 14,4 \\
\hline Depresi Postpartum & & \\
\hline Tidak & 40 & 44,4 \\
\hline Ya & 50 & 55,6 \\
\hline
\end{tabular}

Tabel 2. Hubungan Kondisi Psikososial dan Paritas dengan Kejadian Depresi Postpartum pada Ibu Remaja

\begin{tabular}{|c|c|c|c|c|c|c|}
\hline \multirow{3}{*}{ Variabel } & \multicolumn{4}{|c|}{ Kejadian Depresi Postpartum } & \multirow{3}{*}{ OR } & \multirow{3}{*}{$P$ value } \\
\hline & \multicolumn{2}{|c|}{ Ya } & \multicolumn{2}{|c|}{ Tidak } & & \\
\hline & $\mathbf{n}$ & $\%$ & $\mathbf{n}$ & $\%$ & & \\
\hline Kondisi Psikososial & & & & & & \\
\hline Tidak Beresiko & 17 & 18,9 & 4 & 0,04 & $\begin{array}{c}2.667 \\
(10276060)\end{array}$ & 0.007 \\
\hline Beresiko & 33 & 36,7 & 36 & 44,36 & & \\
\hline Paritas & & & & & & \\
\hline Primipara & 45 & 50 & 32 & 35,6 & $\begin{array}{c}1.333 \\
(0400-4445)\end{array}$ & 0,180 \\
\hline Multipara & 5 & 0,05 & 8 & 14,35 & & \\
\hline
\end{tabular}


Faletehan Health Journal, 8 (1) (2021) 36-41

Hal ini dikarenakan pada kelahiran anak sebelumnya, pengasuhan dilakukan oleh orang tuanya.

Paritas memiliki hubungan tidak langsung dengan kejadian depresi postpartum (Putriarsih et al., 2017). Hasil penelitian ini berbeda dengan hasil penelitian lain mengatakan bahwa salah faktor yang menyebabkan depresi postpartum adalah paritas (Fitelson et al., 2010). Ibu primipara atau ibu yang pertama kali melahirkan memiliki risiko mengalami depresi postpartum (Nurfatimah \& Entoh, 2018). Hal ini disebabkan karena ibu belum memiliki pengalaman dalam merawat anak (Kurniasari \& Astuti, 2015).

Melahirkan untuk pertama kali bagi wanita adalah hal yang sangat menyenangkan dan sekaligus menegangkan. Ketegangan yang dialami dapat disebabkan karena pengalaman pertama. Hal ini juga berpengaruh terhadap proses adaptasi dimana ibu primipara lebih sering mengalami depresi postpartum (Kusuma, 2017). Kekhawatiran ibu dimulai dari sebelum perslainan sampai pasca melahirkan. Hal-hal yang sering dikhawatirkan oleh ibu yaitu nyeri melahirkan, kondisi janin yang dilahirkan, keselamatan diri dan bayinya, perawatan bayi baru lahir, dan proses menyusui. (Nurfatimah \& Entoh, 2018). Ibu yang baru pertama kali melahirkan belum berpengalaman dalam merawat bayi sehingga muncul rasa khawatir, takut dan cemas jika mengalami kesalahan. Ibu primipara akan merasa bingung dalam menjalankan tugasnya sebagai ibu, merasa terbebani, dan merasa tidak memiliki kebebasan dengan kehadiran bayinya (D. A. Fatmawati, 2015).

Wanita yang melahirkan pertama kali menunjukkan rasa sedih, kesal, dan cemas setelah melahirkan (Martínez-Galiano et al., 2019). Hal ini karenakan hormone kortisol meningkat. Hormon ini berpengaruh terhadap suasana hati ibu postpartum (Gillespie et al., 2018). Selain perubahan hormon, bertambahnya peran dan tanggung jawab memerlukan penyesuaian pada masa postpartum. Gagalnya proses penyesuaian masa ini akan membuat ibu menjadi stress dan mudah emosi (Dahro, 2012)

\section{Simpulan}

Penelitian ini dapat disimpulkan bahwa sebagian besar responden mengalami depresi postpartum, sebagain besar primipara dan sebagian kecil memiliki kondisi psikososial berisiko. Terdapat hubungan antara kondisi psikososial dengan depresi postpartum.

\section{Referensi}

Bicking Kinsey, C., \& Hupcey, J. E. (2013). State of the science of maternal-infant bonding: A principle-based concept analysis. Midwifery, 29(12), 1314-1320. https://doi.org/10.1016/j.midw.2012.12.019

BKKBN. (2013). Survei Demografi dan Kesehatan Indonesia 2012. Badan Pusat Statistik.

Borra, C., Iacovou, M., \& Sevilla, A. (2015). New Evidence on Breastfeeding and Postpartum Depression: The Importance of Understanding Women's Intentions. Maternal and Child Health Journal, 19(4), 897-907. https://doi.org/10.1007/s10995-014-1591-z

Çankaya, S. (2020). The effect of psychosocial risk factors on postpartum depression in antenatal period: A prospective study. Archives of Psychiatric Nursing, 34(3), 176-183. https://doi.org/10.1016/j.apnu.2020.04.007

Chabrol, H., \& Challahan, S. (2007). Prevention and treatment of postnatal depression. Expert Rev Neurotherapeutics, 7(5), 557-576.

Christl, B., Reilly, N., Smith, M., Sims, D., Chavasse, F., \& Austin, M. P. (2013). The mental health of mothers of unsettled infants: Is there value in routine psychosocial assessment in this context? Archives of Women's Mental Health, 16(5), 391-399. https://doi.org/10.1007/s00737-013-0360-0

Cirik, D. ., Yerebasmaz, N., Kotan, V. ., Solihoglu, K. ., Akpinar, F., Yalvac, S., \& Kandemir, O. (2016). The impact of prenatal psychologic and obstetric parameters on postpartum depression in late-term pregnancies: A preliminary study. Taiwanese Journal of Obstetrics and Gynecology, 55(3), 374-378.

Coburn, S. S., Gonzales, N. A., Luecken, L. J., \& Crnic, K. A. (2016). Multiple domains of stress predict postpartum depressive symptoms in low-income Mexican American women: the moderating effect of social support. Archives of Women's Mental Health, 19(6), 1009-1018. https://doi.org/10.1007/s00737-016-0649-x

Dahro, A. (2012). Buku Psikologi Kebidanan: Analisis Perilaku Wanita untuk Kesehatan. Salemba Medika. 
Dinwiddie, K. J., Schillerstrom, T. L., \& Schillerstrom, J. E. (2018). Postpartum depression in adolescent mothers. Journal of Psychosomatic Obstetrics and Gynecology, 39(3), 168-175. https://doi.org/10.1080/0167482X.2017.1334 051

Edhborg, M., Nasreen, H. E., \& Kabir, Z. N. (2011). Impact of postpartum depressive and anxiety symptoms on mothers' emotional tie to their infants 2-3 months postpartum: A population-based study from rural Bangladesh. Archives of Women's Mental Health, 14(4), 307-316. https://doi.org/10.1007/s00737-011-0221-7

Fatmawati, A., \& Gartika, N. (2019). Hubungan Dukungan Psikososial dan Perencanaan Kehamilan dengan Kejadian Postpartum Blues pada Ibu Remaja. Jurnal BIMTAS, 3(2), 44-51.

Fatmawati, A., Rachmawati, I. N., \& Budiati, T. (2018). The influence of adolescent postpartum women's psychosocial condition on mother infant bonding. Enfermeria Clinica, 28, 203-206. https://doi.org/10.1016/S11308621(18)30068-8

Fatmawati, D. A. (2015). Faktor Risiko Yang Berpengaruh Terhadap kejadian Post Partum Blues. Jurnal Eduhealth, 5(2).

Fitelson, E., Kim, S., Baker, A. ., \& Leight, K. (2010). Treatment of postpartum depression: Clinical, psychological and pharmacological options. International Journal of Women's Health, 3, 1-14.

Gillespie, S. L., Mitchell, A. M., Kowalsky, J. M., \& Christian, L. M. (2018). Maternal parity and perinatal cortisol adaptation: The role of pregnancy-specific distress and implications for postpartum mood. Psychoneuroendocrinology, 97, 86-93. https://doi.org/10.1016/j.psyneuen.2018.07.0 08

Habel, C., Feeley, N., Hayton, B., Bell, L., \& Zelkowitz, P. (2015). Causes of women's postpartum depression symptoms: Men's and women's perceptions. Midwifery, 31(7), 728734.

Ko, J. Y., Rochkhill, K. M., Tong, V. T., Morrow, B., \& Farr, S. L. (2017). Trends in Postpartum Depressive Symptoms-27 States, 2004, 2008, and 2012. Morbidity and Mortality Weekly Report, 66(6), 153-158.

Kurniasari, D., \& Astuti, Y. A. (2015). Hubungan Antara Karakteristik Ibu, Kondisi Bayi, dan Dukungan Sosial Suami dengan Postpartum Blues pada Ibu dengan Persalinan SC di Rumah Sakit Umum Ahmad Yani Metro Tahun 2014. Jurnal Kesehatan Holistik, 9(3), 115-125.

Kurniawati, D. (2015). Hubungan antara kondisi psikososial ibu pada masa postpartum dan kepauasan ibu terhadap pelayanan persalinan dengan ikatan antara ibu dan bayi. Universitas Indonesia.

Kusuma, P. D. (2017). Karakteristik Penyebab Terjadinya Depresi Postpartum Pada Primipara dan Multipara. Jurnal Keperawatan Notokusuma, 1(1), 15-19.

Lee, H., Park, H., Ha, E., Hong, Y. C., Ha, M., Park, H., Kim, B. N., Lee, B., Lee, S. J., Lee, K. Y., Kim, J. H., Jeong, K. S., \& Kim, Y. (2016). Effect of breastfeeding duration on cognitive development in infants: 3-year follow-up study. Journal of Korean Medical Science, 31(4), 579-584. https://doi.org/10.3346/jkms.2016.31.4.579

Machmudah. (2010). Pengaruh persalinan dengankomplikasi terhadap kemungkinan terjadinya postpartum blues. Universitas Indonesia.

Martin, J. A., Hamilton, B. E., Osterman, M. J. K., Driscoll, A. K., \& Mathews, T. J. (2017). Births: Final data for 2015. National Vital Statistics Reports, 66(1), 1-70.

Martínez-Galiano, J. M., Hernández-Martínez, A., Rodríguez-Almagro, J., Delgado-Rodríguez, M., \& Gómez-Salgado, J. (2019). Relationship between parity and the problems that appear in the postpartum period. Scientific Reports, $9(1), \quad 1-8$. https://doi.org/10.1038/s41598-019-47881-3

Meltzer-Brody, S., Bledsoe-Mansori, S. E., Johnson, N., Killian, C., Hamer, R. M., Jackson, C., Wessel, J., \& Thorp, J. (2013). A prospective study of perinatal depression and trauma history in pregnant minority adolescent. Am J Obstet Gynecol, 208(3), 112. https://doi.org/10.1016/j.ajog.2012.12.020.A

Moynihan, M. (2014). Maternal Attachment in Close Relationships, Mother-Infant Postpartum Bonding, and Mentalization 
Faletehan Health Journal, 8 (1) (2021) 36-41 www. journal.Ippm-stikesfa.ac.id/ojs/index.php/FHJ ISSN 2088-673X | 2597-8667

Megan Moynihan Villanova University in partial fulfillment of the requirements for the degree of Master of Science in Counseling Education and Counseling Dep. May.

Nes, R. ., Hauge, L. ., Landolt, M. ., Eskedal, L., Roysamb, E., Kornstad, Irgens, \& Kristensen, P. (2014). Adaptation to the Birth of a Child with Congenital Anomaly: A Prospective Longitudinal Study of Maternal Well-Being and Psychological Distress. Developmental Psychology, 50(6), 1827-1839.

Ningrum, S. P. (2017). Faktor- Faktor Psikologis Yang Mempengaruhi Post Partum Blues. Jurnal Ilmiah Psikologi, 4(2), 205-218.

Norliza, J., Siti, K. A. ., Emad, A. ., \& Norimah, S. (2018). Depression and coping strategies used by postnatal mothers during the postpartum period. Malaysian Journal of Psychiatry Ejournal, 11(2).

Nunes, A. P., \& Phipps, M. G. (2013). Postpartum depression in adolescent and adult mothers: Comparing prenatal risk factors and predictive models. Maternal and Child Health Journal, 17(6), 1071-1079. https://doi.org/10.1007/s10995-012-1089-5

Nurfatimah, \& Entoh, C. (2018). Hubungan faktor demografi dan dukungan sosial dengan depresi pasca salin. Jurnal Profesi Medika, 11(2), 89-99. https://doi.org/10.1017/CBO9781107415324. 004

Putriarsih, R., Budihastuti, U. R., \& Murti, B. (2017). Prevalence and Determinants of Postpartum Depression in Sukoharjo District, Central Java. Journal of Maternal and Child Health, 33(01), 395-408. https://doi.org/10.26911/thejmch.2017.03.01. 02

Qobadi, M., Collier, C., \& Zhang, L. (2016). The effect of stressful life events on postpartum depression: findings from the 2009-2011 Mississippi pregnancy risk assessment monitoring system. Maternal and Child Health Journal, 20(1), 164-172.

Rahmandani, A., Karyono, \& Dewi, E. K. (2010). Strategi Penanggulangan (Coping) Pada Ibu Yangmengalami Postpartumblues Di Rumah Sakit Umumdaerah Kota Semarang. Jurnal Psikologi Undip, 5(1).
Reeder, S. ., Martin, L. ., \& Griffin, D. . (2012). Keperawatan maternitas: Kesehatan wanita, bayi dan keluarga (18th ed.). EGC.

Santy, Setyowati, \& Novieastari, E. (2011). Pengalaman remaja perempuan single parent di wilayah kerja Puskesmas Kecamatan Panjang Kota Bandar Lampung. Universitas Indonesia.

Sylvén, S. M., Thomopoulos, T. P., Kollia, N., Jonsson, M., \& Skalkidou, A. (2017). Correlates of postpartum depression in first time mothers without previous psychiatric contact. European Psychiatry, 40, 4-12. https://doi.org/10.1016/j.eurpsy.2016.07.003

Tietz, A., Zietlow, A. L., \& Reck, C. (2014). Maternal bonding in mothers with postpartum anxiety disorder: the crucial role of subclinical depressive symptoms and maternal avoidance behaviour. Archives of Women's Mental Health, 433-442. https://doi.org/10.1007/s00737-014-0423-x

Tikmani, S. ., Soomro, T., \& Tikmani, P. (2016). Prevalence and determinants of postpartum depression in a tertiary care hospital. Austin J Obstet Gynecol, 3(2), 1-4.

Young, J., Miller, M. r, \& Khan, N. (2010). Screening and managing depression in adolescents. Adolescent Health, Medicine and Therapeutics, 87-95. https://doi.org/10.2147/ahmt.s7539

Young, R. (2013). The importance of bonding. International Journal of Childbirth Education, 28(3), 11-16.

Yusuff, A. S. ., Tang, L., Binns, C. ., \& Lee, A. . (2015). Prevalence and risk factors for postnatal depression in Sabah, Malaysia: A cohort study. Women and Birth, 28(1), 25-29.

Zaltzman, A., Falcon, B., \& Harrison, M. E. (2015). Body Image in Adolescent Pregnancy. Journal of Pediatric and Adolescent Gynecology, 28(2), 102-108. https://doi.org/10.1016/j.jpag.2014.06.003

Zelkowitz, P., Gold, I., Feeley, N., Hayton, B., Carter, C. S., Tulandi, T., Abenhaim, H. A., \& Levin, P. (2014). Psychosocial stress moderates the relationships between oxytocin, perinatal depression, and maternal behavior. Hormones and Behavior, 66(2), 351-360. https://doi.org/10.1016/j.yhbeh.2014.06.014 